In Memoriam

\title{
Arnaldo Amado Ferreira Filho: Pioneirismo na cirurgia de ombro e cotovelo do Brasil
}

\section{Arnaldo Amado Ferreira Filho: A pioneer in shoulder and elbow surgery in Brazil}

\author{
Arnaldo Amado Ferreira Neto ${ }^{1}$ (1) \\ ${ }^{1}$ Instituto de Ortopedia e Traumatologia, Hospital de Clínicas, \\ Faculdade de Medicina, Universidade de São Paulo, SP, Brasil \\ Rev Bras Ortop 2021;56(1):130-131.
}

Dr. Arnaldo Amado Ferreira Filho nasceu em 01 de novembro de 1930. Natural de São Paulo, graduou-se pela Faculdade de Medicina da Universidade de São Paulo (USP) em 1955, na $38^{a}$ turma. Realizou sua formação em ortopedia no Instituto de Ortopedia e Traumatologia (IOT) do Hospital de Clínicas da Faculdade de Medicina da Universidade de São Paulo (HCFMUSP) em 1956 e logo ingressou como assistente nesta instituição, em 1957.

Cirurgião ortopédico geral, trabalhou no atendimento ambulatorial e cirúrgico em diversas áreas na ortopedia, como cirurgia da mão, coluna, ortopedia pediátrica, tratamento das sequelas de poliomielite, paralisia obstétrica e hemofilia. Tem os títulos de Mestre e Doutor na área de pósgraduação em ortopedia e traumatologia da Faculdade de Medicina da USP nos anos de 1978 e 1984, respectivamente.

Como assistente no IOT HC-FMUSP, exerceu inúmeras atividades assistenciais, administrativas e de pesquisa como fundador e chefe do Grupo de Hemofilia, chefe do Pronto-Socorro e Ambulatório Ortopédico, chefe do Corpo Clínico e da primeira Comissão Científica do DOT.

Mas foi na área da cirurgia do ombro e cotovelo o seu maior destaque. Juntamente com o professor Manlio Marco Mario Napoli, foi fundador do primeiro Grupo de Ombro e Cotovelo do Brasil e América Latina, em 1983. Logo após a sua fundação, assumiu a chefia, atuando até 1998 . Seu interesse pela cirurgia do ombro e cotovelo remonta do início da década de 1960, no atendimento das crianças com sequelas da paralisia obstétrica e nas primeiras cirurgias para tratamento de instabilidade do ombro. Realiza o primeiro proce- dimento de Bristow-Latarjet em 1972, culminando na sua tese de doutorado - Tratamento da Luxação Anterior Recidivante do Ombro pela Técnica de Bristow-Latarjet - estudo com 45 casos, defendida em 1984. A sua tese foi um marco, sendo referência no tratamento da instabilidade do ombro seguida por inúmeros serviços no Brasil. Sua paixão pelo ensino e pela vontade de saber vem do seu ímpeto autodidata e do constante acompanhamento da literatura médica. Uma passagem interessante da sua vida de ensino foi durante o ORTRA, na década de 1990. Depois de uma longa conversa informal com professor Hiroaki Fukuda, palestrante e convidado internacional, o professor Fukuda lhe pergunta: "where did you learn so much about shoulder surgery?". E ele responde com simplicidade: "during my residency training and studying by myself". Sempre esteve aberto para inovações e sempre incentivava aqueles que buscavam o mais novo. Nas inúmeras cirurgias que participávamos, sempre dizia a frase: "o espírito científico não nasce das instituições, mas das pessoas que pensam livremente".

A cirurgia do ombro e cotovelo projetou-o nacional e internacionalmente. Na vida associativa, foi fundador do Comitê de Ombro e Cotovelo da Sociedade Brasileira de Ortopedia e Traumatologia (SBOT), em 1988, e o segundo presidente desse comitê na gestão 90-92, hoje Sociedade Brasileira de Cirurgia do Ombro e Cotovelo (SBCOC). Foi fundador e primeiro presidente da Sociedade Sul-Americana de Cirurgia do Ombro e Cotovelo, hoje Sociedade Latino-Americana de Cirurgia de Ombro e Cotovelo (SLAHOC).
DOI https://doi.org/ $10.1055 / \mathrm{s}-0040-1722279$ ISSN 0102-3616.
(C) 2021. Sociedade Brasileira de Ortopedia e Traumatologia. All rights reserved.

This is an open access article published by Thieme under the terms of the Creative Commons Attribution-NonDerivative-NonCommercial-License, permitting copying and reproduction so long as the original work is given appropriate credit. Contents may not be used for commercial purposes, or adapted, remixed, transformed or built upon. (https://creativecommons.org/ licenses/by-nc-nd/4.0/)

Thieme Revinter Publicações Ltda., Rua do Matoso 170, Rio de Janeiro, RJ, CEP 20270-135, Brazil 
Na ocasião da organização do Journal of Shoulder and Elbow Surgery (JSES), em 1993, foi convidado pelo Prof. Charles Neer a fazer parte desse projeto, como representante da SBCOC nesta prestigiosa revista, sendo editor pela América do Sul até 1996. Em 1994, foi eleito Membro Correspondente Internacional da American Shoulder and Elbow Surgeons (ASES), passando depois a Membro Sênior.

Em 1998, se aposenta de suas atividades institucionais, mas ainda ativo em sua clínica privada e na participação de inúmeros congressos nacionais e internacionais, destacando-se como delegado nos congressos internacionais de cirurgia de ombro e cotovelo (ICSES). Ele sempre foi um verdadeiro pensador independente, escolhendo as melhores ideias de vários autores para desenvolver as suas próprias. Sua paixão e perfeição pelo ensino eram infinitas. Sua dedicação é reconhecida incondicionalmente pelos seus pares. Formou inúmeros colegas pelo Brasil e países afora, aos quais sempre chamava de amigos.

Era leitor contumaz, aprendeu a amar os livros e a história da humanidade com seu pai, Prof. Arnaldo Amado Ferreira, Livre-Docente e Professor Associado da FMUSP.

Homem de família, marido exemplar, pai exigente, sogro, avô e, recentemente, bisavô. Cidadão correto, homem do mundo, querido por muitos.

Aqui fica o seu legado...Aplausos... 